\title{
CHASMS OF COMMUNICATIVE LANGUAGE TEACHING: PERILS OF PUPILS IN PRIMARY SCHOOLS OF BANGLADESH
}

(D) Mohammed
Shamsul Hoque $^{1+}$
(i) J. Karthikeyan
(iD Md. Monjurul
Islam $^{3}$
(D) Md. Kabirul Islam

Received: 2 August 2021 Revised: 6 September 2021 Accepted: 4 October 2021 Published: 29 October 2021

\section{Keywords}

CLT

Curriculum

Health and safety policy

Innovative pedagogy

Learner culture

Parental involvement

Perils of pupils

Teacher empowerment

Young Learners (YL).

\author{
'Associate Professor in English, Daffodil International University, \\ Bangladesh. \\ Email:hoque.eng@daffodilvarsity.edu.bd \\ 'Associate Professor of English, Vellore Institute of Technology, Vellore, \\ India. \\ Email:jkarthikeyan@vit.ac.in \\ ${ }^{3}$ Associate Professor and Head of English, Prime University, Bangladesh \\ Email:monj0603@gamil.com \\ ${ }^{4}$ Professor, Department of MCT, Daffodil International University, Dhaka, \\ Bangladesh \\ Email:kislam@daffodilvarsity.edu.bd
}

\begin{abstract}
The success of the Communicative Language Teaching (CLT) approach at primary schools of Bangladesh has recently been questioned seriously. No measures have yet been taken to remedy the apprehended failure of CLT programs in the country. This inquiry focuses on the perils of pupils in the forms of shaming, failure, and fear for the tyranny of the current CLT curriculum. A mixed research method was used to conduct a comprehensive analysis of the learners' situation through a questionnaire survey with participation of 211 CLT practitioners, an FGD with 12 participants and semistructured interviews with 15 English learners. Along with lack of teacher empowerment mechanisms, other challenges for young learners (YLs) included problem of enduring class rules, their inability to cope with difficult texts, fear of failure in lessons, tests, and physical and psychological sufferings inflicted on them during, before and after the delivery of the lessons. The findings reveal the need of a modified CLT curriculum with provisions for innovative pedagogy, learner care and learner empowerment. Provisions for use of L1 Bangla in lesson delivery, inclusion of learner culture and local context in the teaching-learning of English are recommended to ensure expected outcomes.
\end{abstract}

Contribution/ Originality: This empirical study conducted across Bangladesh regressive sub-districts disclosed that the teachers not only lacked teaching competencies but also failed to update and provide a beneficial learning environment for the school children. Language learning is also traumatized due to their worst economic conditions and sub-standard facilities in the school.

\section{INTRODUCTION}

Bangladesh shares the legacy of English Language Teaching (ELT) in the sub-continent since the passage of Macaulay's Minutes on the Education Act of India 1835. For about a century and a quarter, the ELT in the region now known as Bangladesh, after its independence in 1971, used to be delivered through traditional GrammarTranslation Method (GTM). Until today, ELT curriculum failed to train a teaching-force with English language skills for communicative purposes (EIA-English in Action, 2009; Erling \& Hamid, 2016; Hassan, 2013). Sultana (2018) stated that Bangladesh had been trying to improve the quality of ELT since the last decade of the last 
century to raise a workforce with English language skills required by the job market of the $21^{\text {st }}$ century. The emergence of CLT approach during the 1970s (Canale \& Swain, 1980; Richards, 2006) and the rising socioeconomic demands for manpower competent in English inside and outside of the country gradually impacted the whole approach to ELT in Bangladesh. This motivated the policymakers to introduce the CLT approach from primary to tertiary levels in the 1990s (Hossain, Nessa, \& Kafi, 2015). But studies including Karim (2004); Chang (2010); Ansarey (2012); Kirkwood (2013); Karim, Mohamed, and Rahman (2017) and Burton, Eyres, and McCormick (2019) reported that CLT programmes have been ineffective, unproductive and unsuccessful in Bangladesh. The ELT deterioration has continued to decline year on year for five decades since 1971. With 'limited empirical evidence' (Hassan, 2013; Kirkwood, 2013) there is no credible findings on CLT at the primary school level. No research has been conducted on the English learner issues including

- Academic problems they must put up with.

- Physical and psychological stress they deal with at school.

- Fear and fright they sufferer with.

Considering these gaps, this study focuses on the issue of learner distress leading to their under-achievement, low motivation and fear of failure in the rural primary schools of Bangladesh.

The research questions of the study included:

1. What are the factors of low or no achievement in learning English by the socioeconomically disadvantaged primary pupils of rural Bangladesh?

2. How can the stress resulting from physical and psychological distress of English learners be addressed?

The study investigated evidence of the damaging effects of the CLT approach leading to physical and emotional sufferings of young learners of English. It also attempted to endorse the way out to amend such damage to help implement the CLT curriculum in a positive and healthy manner in the country.

\section{PROBLEMS EXPLAINED}

Recent research report between policy and practice (Burton et al., 2019) revealed that the hurriedly planned move to modernise the ELT curricula, teaching materials, and teacher training to implement CLT in Bangladesh, unfortunately mismatched with the need. CLT had also experienced similar difficulties and challenges in different countries like China, Indonesia, India, Korea, Malaysia, Pakistan, Thailand (Ellis, 1996; Karim, 2004; Li, 1998; Liao, 2000; Rao, 2002; Savignon, 2002; Yu, 2001). “The new curriculum, though it aimed to develop students' oral communication skills, the teachers' own limitations in this respect were problematic” Farooqui (2014)(p. 251). This picture on "teachers' own limitation" is true with reference to the CLT scenario in Bangladesh. These limitations are a result of many factors including teacher limitations, environmental incompatibility, lack of Teachers' Continued Professional Development (TCPD), Un-user-friendly teaching materials, lack of electricity supply, and poor socio-economic backgrounds of the Young Learners (YL) of English that are briefly discussed below. Similar findings have been reported in Carless (2004) and Julie (2013) in their research on CLT in Hong Kong, Jahbel (2017) on Libya, Exley (2004) on Indonesia and Hussain (2017) on Pakistan. According to Richards and Rodgers (2001) "CLT appeals to those who seek a humanistic approach to teaching, one in which the interactive process of communication receives priority (p. 172)."

However, this phenomenon is absent in the majority of schools in Bangladesh and all schools in rural Bangladesh. English in Action (2009) reports on the 'cynical element' of English language incompetence among the 'lecturers and tutors' in charge of training the CLT teachers of Bangladesh. CLT approach demands an 'English environment' where teachers are equipped with native speaker's competence in English so as to be effective during teaching and learning English. However, it is not possible for a country like Bangladesh to create such environment or produce such teachers. The EIA- English in Action (2009) again reported the lack of environment, malpractice of teachers doing display work for children as a proof of practicing CLT at some 'elite English Medium schools.' EIA 
added (p.3) that even seven English supplementary readers provided by UNICEF for CLT at primary levels were no longer to be found in the bookshelves of any primary school of the country.

Bangladesh is yet to show any improvement on its continued deterioration (Burton et al., 2019; Hasan, 2004; Rahman \& Rahman, 2012; Shrestha, 2013). However, declarations to prioritise English Language Teaching in Bangladesh have been made at different times (Erling \& Hamid, 2016) and textbooks were written and re-written in 1976, 1999, and 2006 in response to these declarations and 'ambiguous' policies, but a clear Act on language teaching is yet to be seen to suit the CLT approach of teaching English from the 1990s. EIA reports that Bangladesh is a $100 \%$ monolingual country, which provides the opportunity for a natural lack of an 'English Environment' (p. 3), which is almost a pre-requisite for implementing CLT. Additional reading materials are not available. Teachers' pedagogic competence is seriously questionable. Motivation of both teachers and YLs is close to nil. With no parental involvement, poverty, perennial problems of boredom, fear and fright of YLs falling victims of physical and psychological punishment coupled with authority negligence toward CLT implementation have pushed the literally 1,63,36,096 YLs (Directorate of Primary Education, 2019) of CLT to a point of nihilistic nostalgia in antipathy about getting on with CLT.

This study focuses on the problems like learner stress and perils that the YLs of CLT in rural primary schools of Bangladesh have to put up with without any care and consideration from any 'guardians' to come with a solution.

\section{THE STUDY CONTEXT}

Bangladesh is a middle-income country (World Bank, 2021) with concentration of the rich elite in the urban areas and the poor living in the rural regions. The area of the country is $148,460 \mathrm{~km}^{2}$ and population 163 million The district of Kurigram is in the north-western corner of Bangladesh with an area of 2,245.04 $\mathrm{km}^{2}$ and a population of 2,069,273 with a population density of $920 / \mathrm{km}^{2}$.The three sub-districts of Phulbari, Rajarhat and Kurigram Sadar shown in red on the map below are adjacent to each other in the west of the district with a total area of $609.33 \mathrm{~km}^{2}$ and a population of 5, 39, 668. The selected research site is criss-crossed by major rivers like Tista, Dharla, Brahmaputra and their tributaries.

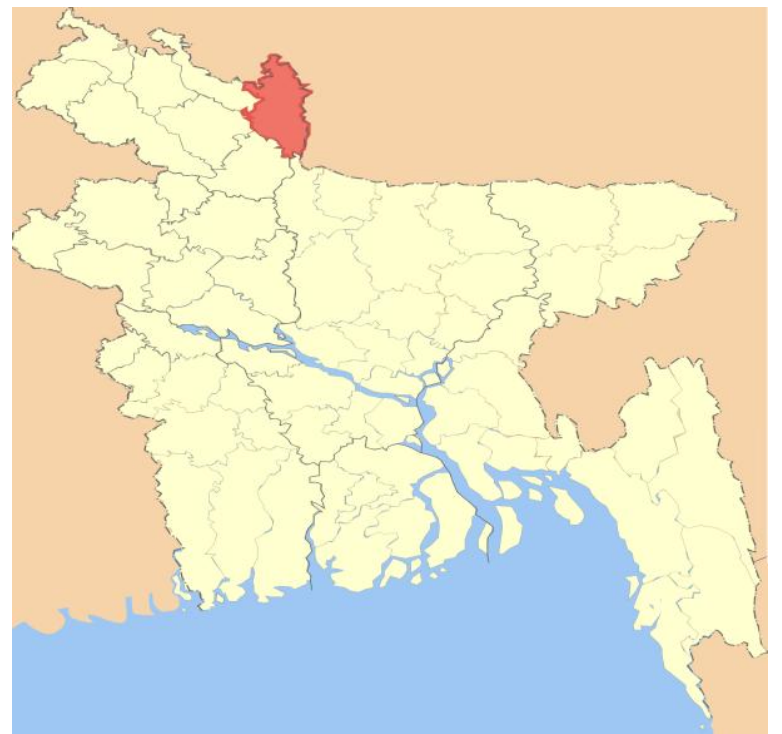

Figure-1. Kurigram-the research district in the map of Bangladesh Highlighted in red.

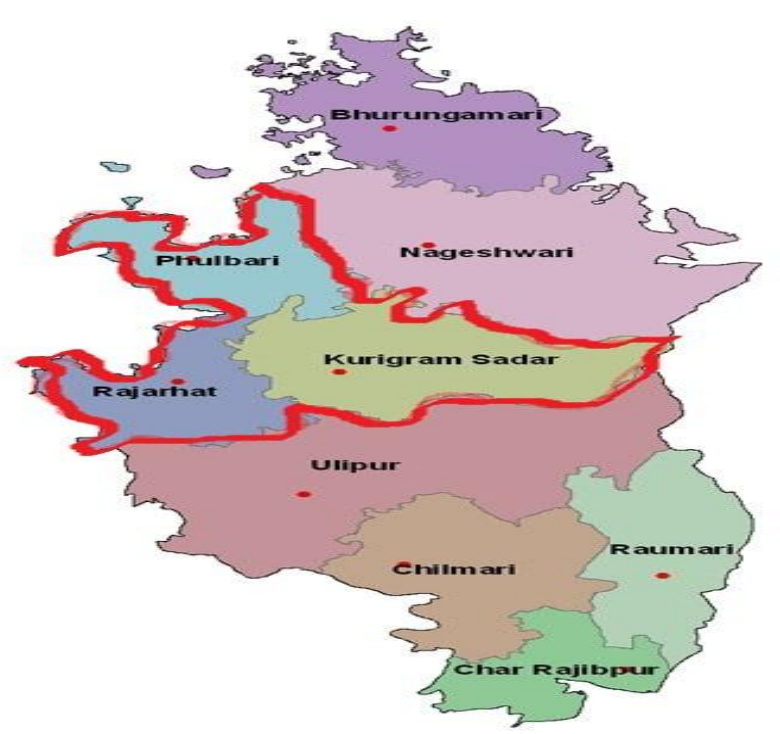

Figure-2. The map of research sites- the three sub-districts of Kurigram district - highlighted in red.

\section{THE STUDY DESIGN}

This study adopted the mixed method research design. This design facilitated the researchers to evaluate the existing situation from the practical experiences of CLT delivery at the time of study (Creswell \& Plano, 2007). It also helped in painting the bigger picture of the research problems from different viewpoints as it incorporated 
qualitative data from open-ended sources and quantitative data from close-ended sources in a solitary inquiry (Creswell, 2014). This design has been appreciated with many jargons like "integrating, synthesis, quantitative and qualitative methods, multi-method, and mixed methodology" but the commonly used term is - mixed methods (Tashakkori \& Teddlie, 2010).

Credible mixed method investigation necessitates combination of different perceptions with the help of 'quanqual' data from framing the research questions, to sampling, data collection, analysis, and, lastly, to elucidation (Yin, 2006). Mixed method researchers adopt a "non-purist or compatibilist or mixed position" (Johnson \& Onwuegbuzie, 2004) to facilitate blending multi- constituents of research design to figure out a bigger picture of their research problems.

This method is the combination of two leading research genres. It counterbalances the inadequacies of one single mode ensuring more valid and credible findings of a research. This design includes analysis of relevant quantitative data for teacher perception from the questionnaire survey participated by 211 CLT practitioners; those of learner perception from the qualitative data of the interviews with $15 \mathrm{YLs}$; and supported by qualitative data from the FGD participated by 12 different stakeholders of CLT.

This study refers to Bourdieu (1997) 'model of cultural reproduction' and the 'theory of structure-habituspractice' and considers 'economic, cultural and social capital' to deduce that in the rural social space, learners are equipped with a typical type of educational habitus which exposes their social position as well as regulate their educational performance. Learning is also subject to this educational habitus and social position which dictate their performance in English, in this case, poorly. Low socio-economic class, rural cultural uniqueness, sociolinguistic difference, and a context far from the requirements of the CLT approach led to poor performance which, in turn, leads to problems like learners' emotional, academic, and social sufferings (Bernstein, 1973). These issues have remained unaddressed in any research on rural English learners of Bangladesh. This study is thus providing a new dimension of research in ELT with particular emphasis on CLT in the rural primary schools of Bangladesh.

\section{PARTICIPANTS}

To conduct an in-depth study, a questionnaire survey, an FGD and semi-structure interviews were used to collect data. For questionnaire survey, 211 CLT teachers participated from schools in river-eroded and most disadvantaged rural schools of three north-western sub-districts of Rajarhat, Fulbari and Kurigram as seen in Figures 1 and 2. A total of 89 CLT teachers from Rajarhat sub-district, 78 from Fulbari and 44 from Kurigram Sadar responded to the survey. Data were also accrued from an FGD with 12 participants that included two UEO/AUEO, two Head-teachers, two CLT teachers, two non-CLT teachers, two parents/guardians and two laymen. Semi-structured interviews with 15 students from grades four and five were also conducted.

To obtain an all-inclusive picture focusing on pupil anxiety and stress out of CLT approach in the primary schools of Bangladesh, open-ended questions were used to collect quantitative and qualitative data to unwrap a new dimension of learner stress for research on CLT in Bangladesh. The survey involving 211 CLT teachers provided sufficient quantitative data to capture the teacher perception of the learner distress; while the interviews with 15 YLs provided first-hand information about the focus of the study and the FGD data validated the findings from the survey and the interviews. The combination of 'Quan-qual' findings helped paint a holistic picture of the identified research problem.

\section{DATA COLLECTION PROCEDURE}

For the teachers to participate in the questionnaire survey and the FGD, personal contacts and/or permissions from relevant authorities at sub-district levels were obtained. Most of the surveys with 211 CLT teachers were held on weekends or on days off for the teachers to make it easy for them to participate. On a few occasions, groups of 57 teachers were organised and research assistants and/or the researcher visited individual teachers either at their 
schools or at any other convenient places to collect data. The FGD with two head teachers, two CLT teachers, two non-CLT teachers, onesss Upazilla Education Officer (UEO), one Assistant Upazilla Education Officer(AUEO), two parents, an EIA Master Trainer and a layman was held at the end of the questionnaire survey. A total of 15 YLs from grades four and five were interviewed with a set of informal questions to explore their perceptions and experience of learning English at school.

However, it was quite difficult to organize all the participants and the research events. The time taken was longer than expected, as the area of study covered more than $609.33 \mathrm{~km}^{2}$ (Hossain, 2012) which was mostly rivereroded areas in the north-western sub-districts. The FGD was held at the LGED campus of Chhinai Union of Rajarhat sub-district, a location in the central point of all regions. The interviews of 15 YLs of English from local primary schools were held at the same venue. All ethical issues including parental permission for interview with YLs were addressed properly.

\subsection{Data Analysis}

The quantitative data accrued from the survey were scrutinized using SPSS (Statistical Package for Social Scientist). The qualitative data obtained through the questionnaire, the FGD and interviews were analyzed through coding and categorizing. Triangulation of the findings was done to increase the validity, reliability and integrity (Bashir, Afzal, \& Azeem, 2008; Cohen, Manion, \& Morrison, 2000) of the study following methodological triangulation method. This study ensured cross-validation using qualitative and quantitative analyses to scrutinize the same aspects of the research problem (Jick, 1979). Mixing of data analysis techniques was considered to be complimentary (Greene, Caracelli, \& Graham, 1989) in establishing a bigger picture of the research problem. The eventual aim of the mixed method analysis was to shape up a context based on lived experiences of the CLT teachers, YLs of English, educational administrators, parents/guardians and laymen involved directly and indirectly with the research problems to be probed (Dixon-Woods, Agarwal, Jones, Young, \& Sutton, 2005).

Bazeley (2013) advocates for a mixed method design whereby data analysis was possible through integration of data accrued from different research tools to synthesize, combine and convert data from one form to another (Table 1). Thus, this analysis incorporated both qualitative and quantitative research approaches required to understand the phenomenon in minute details making best use of the collected data (Bryman, 2004).

Table -1. Correlation between research question and corresponding data

\begin{tabular}{|c|c|c|c|}
\hline RQ No. & Research Question & $\begin{array}{l}\text { Corresponding data } \\
\text { tools }\end{array}$ & Summary of Findings \\
\hline 1 & $\begin{array}{l}\text { What are the facts of } \\
\text { pupils' perils in learning } \\
\text { English following CLT } \\
\text { approach at the rural } \\
\text { primary schools of } \\
\text { Bangladesh? }\end{array}$ & $\begin{array}{l}\text { Questionnaire survey, } \\
\text { interview with YLs } \\
\text { and FGD }\end{array}$ & $\begin{array}{l}\text { Teachers' poor motivation, } \\
\text { Teachers' poor English language skills } \\
\text { Lack of learner motivation } \\
\text { Absence of health and safety measures } \\
\text { Lack of learner care } \\
\text { Learner fear of emotional stress and physical punishment } \\
\text { Total lack of learner motivation and home support } \\
\text { Lack of competent teacher and user-friendly materials } \\
\text { Lack of electricity and IT support } \\
\text { Learner disengagement, boredom and poverty issues } \\
\text { No parental involvement in children's education } \\
\text { Lack of English environment } \\
\text { A general apathy towards English lessons }\end{array}$ \\
\hline 2 & $\begin{array}{l}\text { How can the stress } \\
\text { resulting in physical and } \\
\text { psychological distress of } \\
\text { the English learners be } \\
\text { addressed? }\end{array}$ & $\begin{array}{l}\text { Questionnaire survey, } \\
\text { interview with YLs } \\
\text { and FGD }\end{array}$ & $\begin{array}{l}\text { Modified CLT curriculum with user-friendly teaching } \\
\text { materials } \\
\text { Competent and committed CLT teachers with passion for } \\
\text { English teaching at primary level } \\
\text { Effective health and safety policy at every school } \\
\text { Useful Infrastructure for CLT lessons } \\
\text { Useful IT equipment and supply of electricity } \\
\text { PTA-parents teachers association } \\
\text { Provisions for bilingualism CLT lesson delivery } \\
\text { Enjoyable lessons with playful activities }\end{array}$ \\
\hline
\end{tabular}




\section{FINDINGS}

Data related to leaner stress and anxiety revealed a grim picture of learner displeasure, disengagement, boredom and fear of punishment and shaming in CLT lessons in the hard-to-reach, river-eroded rural primary schools of Bangladesh. In addition to these focal points of 'pupils' perils' the findings of this investigation presented supplementary evidence of teacher incompetence and negligence of duty, absence of effective guidance and supervision mechanism, poverty-related issues of learner incapacity, academic impediments resulting in demotivation and deprivation.

The detailed findings of the study are presented in the following sections.

\subsection{Questionnaire Survey}

The findings from the questionnaire survey were analysed considering the four categories that emerged from the collected data. To draw a realistic picture of the CLT curriculum, the categories of data were summarised as follows:

- Teachers' poor motivation,

- Teachers' poor English language skills

- Lack of Learner motivation

- Absence of any health and safety measures to ensure leaner welfare

\subsubsection{Teachers' Poor Motivation}

Teacher motivation is a very important aspect (Stirling, 2014) in all teaching situations. The findings from all three research tools namely the survey, the FGD and the interview, revealed that the array of teacher motivation in CLT curriculum at primary schools in rural Bangladesh was extremely poor. This is reported clearly through the statement of Teacher 2 participating in the FGD, who stated:

"It is not possible because teachers have not been given training at all. Even I am not properly trained. Although my English is good, I cannot teach CLT textbook because it is very hard for me. Most CLT teachers can't speak and never speak English in the class. Teachers are very reluctant to use English in the lessons. Parents in village do not care about their children's education. Children do not like English lessons. CLT in the village environment is impossible. How can CLT curriculum be implemented?"

This sums up the whole scenario of CLT in Bangladesh. All participants in the FGD, the findings from the survey and the interview resonated similar views as expressed in the statement of the T2 participating in the FGD.

\subsubsection{Teachers' Poor English Language Skills}

The data on language skills requiring considerable improvement is presented in Figure 3. The results indicate the teachers' acknowledgement of their own language deficiency. Figure 3 shows that 202 (96\%) out of 211 respondents felt that they needed a range of improvement of the English language skills of listening, speaking, and communication. Nine teachers $(4.26 \%)$ reported that they needed to improve their reading and writing skills, which begs questions as per the report by Burton et al. (2019). This report by EIA consultants clearly reveals that most of the CLT teachers of rural primary schools in Bangladesh themselves find it difficult to understand the grade 5 text, English for Today, let alone teaching its contents. In the FGD, the UEO and the AUEO reported.

"CLT teachers don't understand English when spoken in real language situations; they cannot speak English at all. How can they conduct any CLT lesson as per syllabus needs?”

The Head-teachers in the FGD commented,

"The primary English teachers can speak English in a disjointed way, which is far less than communication. They are culturally hesitant to speak English in public." 
A total of $60 \%$ of YLs unequivocally claimed in the interview that their teacher didn't/couldn't speak English in the lessons. Eventually all the YLs stated their English teachers did not use English in delivering English lessons. Seven out of fifteen (46.66\%) pupils reported that the English teachers never taught them to speak English, but they rebuked and sometimes they beat them for their inability to speak English during the lessons. A dichotomy between the principles of equality, rules of health and safety and cruelty in the name pedagogic authority of the teachers seemed to have turned the scenario of safe environment into a nightmare for the YLs. This undesirable practice of punishment in the form of corporal and emotional took place because of the teacher incompetence. The reality is that the incompetent teacher felt uncomfortable and uncertain of their authority in the classroom and, hence, took recourse to a regime of fear and fright resulting in the perils of pupils.

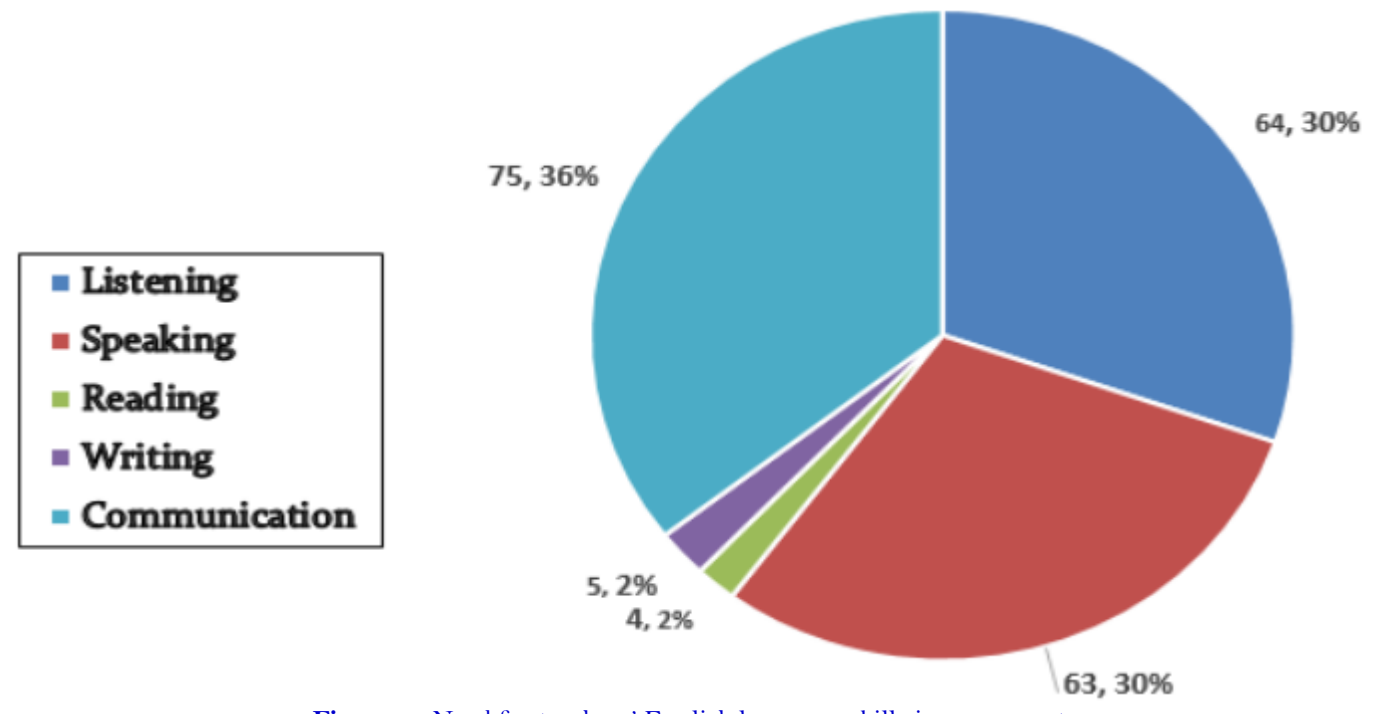

Figure-3. Need for teachers' English language skills improvement.

\subsubsection{Lack of Learner Motivation}

Over 93\% of YLs displayed no motivation at all in learning English for various reasons. Student 1 recorded 11 out of his 25 statements, showing concern about their English learning skills, as all the 11 statements were demotivating and painting a picture full of fear and fright. For example, in answer to Question $2\left(\mathrm{Q}^{2}\right), \mathrm{S}_{1}$ stated:

"Ami English bujhi na, sir. Apni Banglai bolen. Ami uttor dite parbo." (Researcher's own translation: I don't understand English well, sir." I'll answer your questions if you speak in Bangla." From now on all the statements will be presented in translation).

$\mathrm{S} 1, \mathrm{~S} 2, \mathrm{~S} 4, \mathrm{~S} 5, \mathrm{~S} 7, \mathrm{~S} 8, \mathrm{~S} 10, \mathrm{~S} 11, \mathrm{~S} 13, \mathrm{~S} 14$ and $\mathrm{S} 15$ reported their inability and dislike in reading and speaking English as they found it 'very difficult.' They added that they felt like 'there was no English class in school.' They fearfully reported that their "English teachers told them off badly ('Gailai' in Bangla) and, sometimes, hit them." They also stated that there was “nobody at home to help them read English." Statements like “Our teacher doesn't speak English during the lesson, but we have to speak it." Therefore, leaner motivation as per the findings in all three research tools was at the lowest at all primary schools in the location of this study. Moreover, a scenario of learners' perils, fear and fright emerged during the semi-structured interviews. The FGD too reported a total of $25.58 \%$ learners who felt the perils, out of which fear and disengagement was identified with $11.30 \%$ and those with learner motivation was $14.28 \%$ expressing their concerns for perils and demotivation of learners resulting in disengagement and disruption in their education especially English.

More horrid statements from some of the interviewees were: S-9: "I don't want to learn English. What's the point? In the end of the day, I'll have to be a day-labourer." S-13 informed, "I am always scared in the class. I am scared of being asked to say something in English in the class. I feel shy about failing to respond." S-14 opined, "I feel I won't come to school again. But my parents keep on pressurising me." S-15 added, "I spend time in the 
English class in fear. I don't know when my turn will come to be ashamed of myself." 93.33\% of the participants stated such negative comments with reference to English lessons at grade four and five. This led to paint a punitive picture of perils and punishments, fear and distrust, disrespect and disrepute, shame and shamble about English lessons in the primary schools of rural Bangladesh.

\subsubsection{Absence of Health and Safety Policy}

Health and Safety policies are vital for any educational setting. It is very important that pupils feel safe and free of any abuse to venture any method of learning activity including asking questions and making mistakes. Unfortunately, it is a common knowledge in Bangladesh that no government run primary schools have any such Health and Safety policy in place to guarantee health and safety of both children and adults. But it is a comprehensible fact that teachers at primary schools of Bangladesh have the social 'license' to have absolute control over the life of their students, and hence, they are free to inflict verbal abuse and corporal punishment to the children under their care. The issue was discussed in the FGD and the teachers and headmasters, who participated in the FGD, avoided responding to the issue for obvious reasons. But the UEO strongly reported, "Teachers can be cruel on students with verbal abuse and corporal punishment." The parents claimed that their children sometimes complained about teachers' verbal abuse and physical 'torture' in the school. The layman agreed. But the horrendous picture of a tortuous regime in the school, particularly in the English lessons, was painted by the blatant, sometimes painful, statements of the pupils interviewed. (See Table 1 and Figure 4).

\subsection{Findings from the FGD}

FGD is a useful research tool to have an in-depth perception into different sentiments and opinions among different stakeholders of any research project. FGD is often used for qualitative research to reach an in-depth understanding of issues related to social and academic problems. This method helped us acquire data from an intentionally selected cluster of personages rather than from a statistically demonstrative sample of a wider population (Breen, 2006; Luke \& Goodrich, 2019).

The findings from the FGD of this study revealed the teachers' lack of

- Confidence in the delivery of CLT.

- English language proficiency.

- Considerable familiarity with CLT.

- Non-use of technology in teaching.

- Motivation.

A total of 168 comments/opinions/statements were obtained from the FGD. The comments were coded to select seven categories as mentioned in Table 2. These seven categories were again put into three broad categories as lack of CLT environment (42.85\%), lack of teacher empowerment (42.83\%) and a lack of learner motivation $(14.28 \%)$.

The FGD findings reflect those from the survey and the interview in most cases.

\subsection{Findings from the Semi-Structured Interview}

A total of $88.23 \%$ of the YLs of English in the primary schools of Bangladesh revealed during the interviews that they were not motivated in learning English at their school. All 100\% reported that they found the English textbook 'too difficult'. All 100\% reported that their English teachers did not speak English during their lessons. All $100 \%$ expressed that there was nobody in their families to help them read English at home. A total of $82.35 \%$ failed to enjoy any English lessons. All 100\% of the YLs had no electricity supply in their schools and no ICT materials were used for their learning English as portrayed in Figure 4. 


\begin{tabular}{|c|c|c|c|c|c|c|c|c|}
\hline Categories of comments & $\begin{array}{c}\text { Responses } \\
\text { CLT teachers }\end{array}$ & Parents/guardians & $\begin{array}{c}\text { Non-English } \\
\text { teachers }\end{array}$ & Laymen & $\begin{array}{l}\text { UEO/ } \\
\text { AUEO }\end{array}$ & $\begin{array}{c}\text { Head/ } \\
\text { Master Trainer }\end{array}$ & Total & $\%$ \\
\hline Lack of English Environment & 5 & 4 & 5 & 3 & 6 & 5 & 28 & $16.66 \%$ \\
\hline Poor setting & 4 & 3 & 5 & 3 & 5 & 3 & 23 & $13.69 \%$ \\
\hline Parental Involvement & 5 & 3 & 4 & 2 & 4 & 3 & 21 & $12.5 \%$ \\
\hline Difficult instructional materials & 3 & 1 & 2 & 1 & 4 & 3 & 14 & $8.337 \%$ \\
\hline Lack of TCPD & 4 & 4 & 5 & 4 & 3 & 4 & 24 & $14.28 \%$ \\
\hline English Subject Teacher & 2 & 2 & 3 & 2 & 2 & 4 & 15 & $8.92 \%$ \\
\hline Lack of Learner motivation & 5 & 3 & 4 & 3 & 4 & 5 & 24 & $14.28 \%$ \\
\hline Learner fear \& disengagement & 1 & 9 & 4 & 3 & 1 & 1 & 19 & $11.30 \%$ \\
\hline
\end{tabular}

$\frac{\text { Learner fear \& disengagement }}{\text { Note: Broad Categories: ULack of CLT Environment }(4.2 .85 \%) \text {. }}$

ack of Teacher Empowerment (42.83\%). 
This picture becomes vivid from interviewee comments like, "My teacher doesn't speak English but they force us to read and speak English in the class"; "My teacher hits me if I ask her the meaning of a word in English”; “Teachers come to class, ask us to read or copy the text and sleep on the chair”; “I can't read English and I don't like to read”; Sometimes I feel like fleeing away from the English lesson” etc. These statements prove that the YLs suffer emotionally and physically at the tyrannical hands of CLT approach getting implemented in Bangladesh ELT.

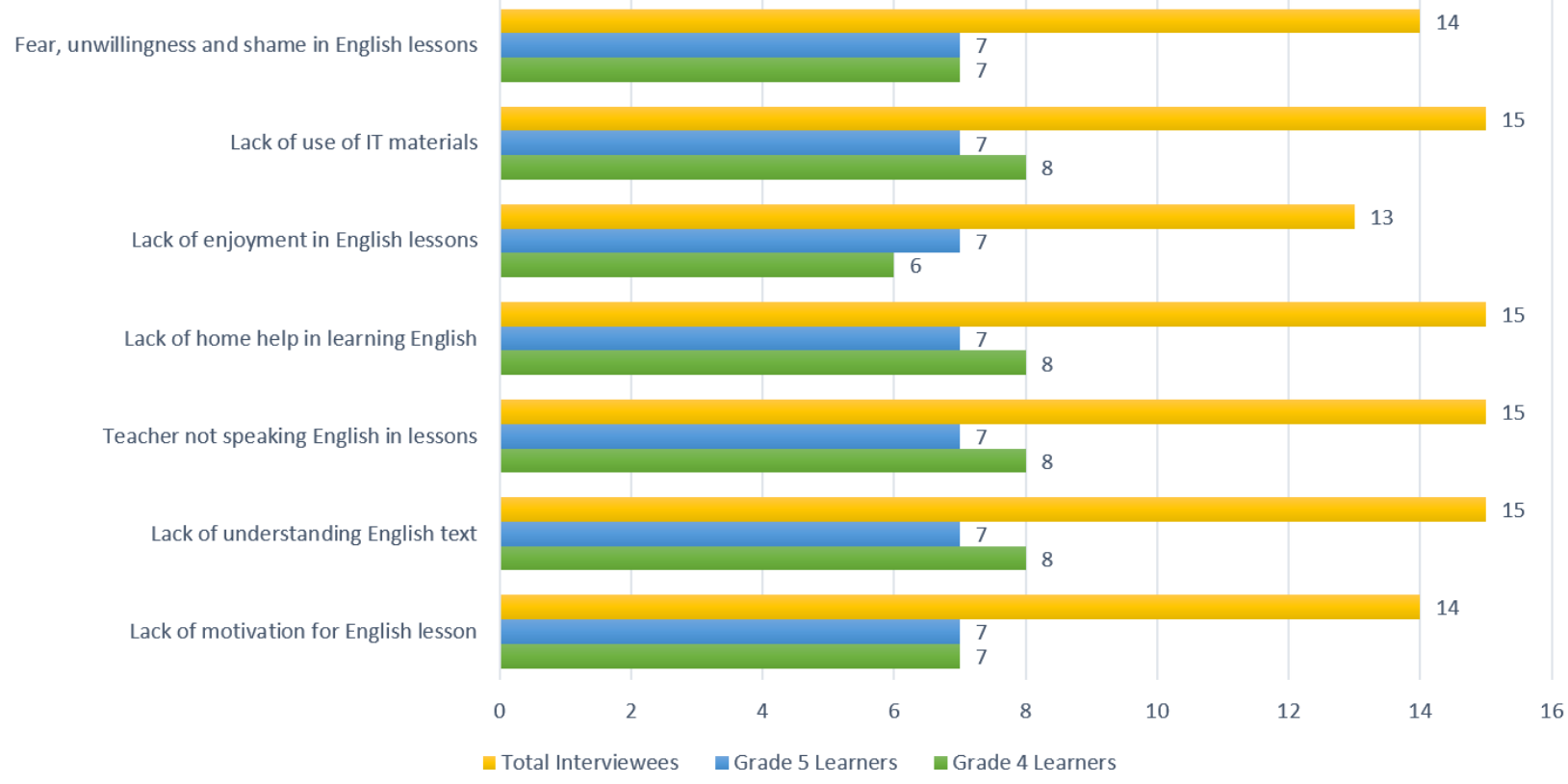

Figure-4. Findings from the interview with YLs.

Figure 4 presents the fact of fear and fright of the English learners in attending the English lessons as they, firstly, lack motivation owing to parental disinterestedness, family poverty, unhelpful English curriculum, verbal and physical 'abuse' inflicted on them by the unmotivated and untrained teachers. 14 out of 15 interviewees replied this question on verbal and physical abuse by the teachers and all of them reported that they are the victims of a tortuous regime in the English lessons. Teachers participating in the survey and the participants in the FGD understandably remained quiet on this aspect of the investigation. But with reference to the field notes of the study there were evidence of an effort for all of them to avoid discussion on this issue of 'abuse' in the English lessons.

\subsubsection{Perils of the Pupils}

Pupils from poor socio-economic circumstances in the river-eroded rural Bangladesh, as in other rural communities in the developed and developing world, are predicted to be doubly disadvantaged during the Covid-19 pandemic. Their geographic location has constrained their access to the IT and ICT and other technological resources. These hindrances have affected their schools as well. The schools have never been and will not be in near future in a position to offer online teaching due to their inadequate technological infrastructure, provisions and expertise. Even if virtual teaching-learning were accessible, socioeconomic detriment of many YLs in rural Bangladesh cannot afford necessary devices or internet service to access virtual teaching. Despite the varied discourses on the development of Bangladesh and of a looming middle-income socio-economic status (Raihan \& Han, 2013; World Bank, 2021) many families in rural Bangladesh struggle to arrange two square meals a day. These families have also been hit hard by the pandemic owing to the loss of jobs of their main income-earners. YLs of English in such families may worry more about the basic needs for survival than disrupted education now and in future. 
Therefore, to implement equal opportunities for all English learners, most of the requirements of CLT approach, if not all, should be in place in the rural primary schools of Bangladesh. Teachers should be trained properly to be able to tackle any issues emerging out of the 'social habitus' and 'cultural capital' situations, involve parents in their children's education despite their limitations in terms of uniqueness of their sociolects for communication and poverty and ensure learner empowerment through creative, context-sensitive and need-based teaching-learning manners and materials. All facilities including supply of electricity, Ed Tech equipment, mid-day meals for the children and an effective health and safety policy should be in place. And none but the government of the country should bear the responsibilities to ensure all provisions to implement policies of equal opportunities for all. The responsibility for teaching-learning of English is a government priority now and, hence, the ultimate responsibility falls on the government language policy and its mechanisms.

\section{DISCUSSION AND INTERPRETATION}

The major findings of the questionnaire survey revolved around teachers' poor motivation, poor English language skills, lack of learner motivation and absence of health and safety measures to ensure leaner and worker welfare. Despite teachers having considerable academic potential, the participants in the survey report reported the

- $\quad$ Lack of appropriate CLT training and provisions for TCPD.

- Lack of English environment and infrastructural facilities for holding English lessons.

- Teachers not taking interest in teaching English using IT equipment.

- Lack of parental interest in their children's education.

The FGD revealed a bigger picture reflecting similar weaknesses including.

- Scathing criticism of the supervision and monitoring system of the CLT programs hinting at the TCPD.

- Deficiency and unproductive teacher training.

- Unhelpful home and school environment.

- Pupils distracted from the 'CLT regime' at school.

- Parental disinterestedness and poverty.

All these findings paint a negative CLT situation which forces the YLs to get demotivated in schooling and let alone learning English.

The findings from the interviews with CLT learners reverberated the findings from the survey and the FGD. A serious issue yet to be investigated by any research should include

- Dimension of "pupils' perils" of a regime of 'verbal abuse'.

- Emotional damage from the teachers for the YLs' 'inability'.

- YLs' to actively participate in the English lessons.

These 'perils' include anxiety of teacher rebuke in English lesson, apprehension of inability to comprehend English lesson, trepidation of publicly 'naming and shaming' by the teacher, fear and fright emotional anguish and, in many cases, corporal punishment.

The summary of the reports of the survey presented in Figure 5 presents a clear picture of the predicaments of the CLT teachers owing to their poor English language proficiency, lack of pedagogic preparation and TCPD, absence of an effective supervision system to be able to deliver the current CLT programs effectively. Combined with the data from the survey, the FGD and the interview reflect similar findings through $42.45 \%$ of the total 28 categories of data accrued. The YLs experience has been reported very negative. A total of $21.42 \%$ respondents considered poor learner motivation, lack of English environment and lack of parental involvement responsible to raise a question about learner disempowerment in CLT lessons. A total of $28.57 \%$ respondents believed that psychological and physical hazards of the YLs at school happened because of the reasons like

- 'Teacher's torture' in teaching English.

- $\quad$ Lack of English environment. 
- Difficult and uninteresting textbook.

- Learners' additional home responsibility.

- No home help in reading English.

- Parental poverty.

- Unaffordable IT materials.

- Pupils' inability to participate in English lessons.

- Pupils' distress out of emotional abuse and corporal punishment in English lessons.

Findings from the Survey

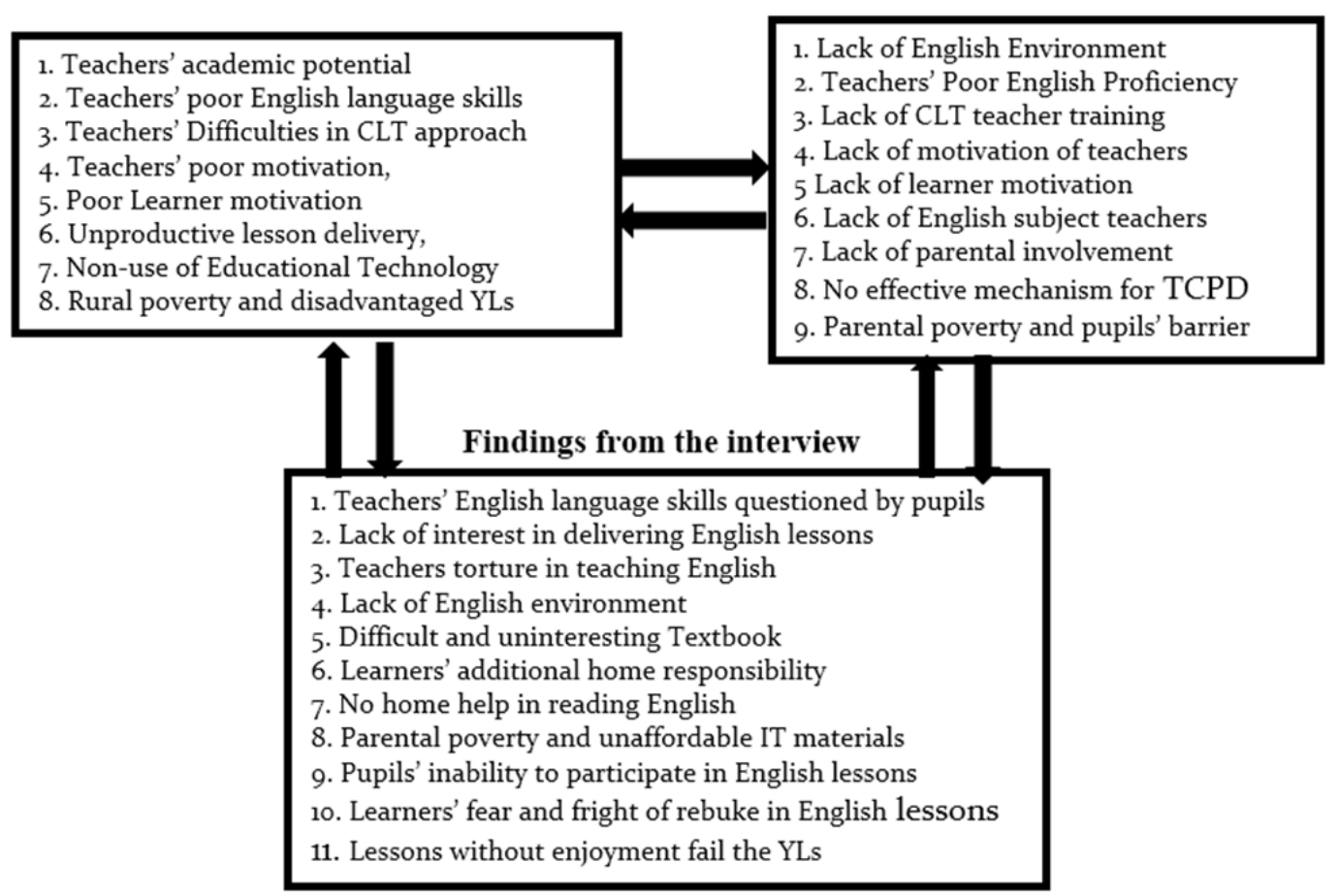

Findings from the FGD

3. Lack of CLT teacher training

4. Lack of motivation of teachers

5 Lack of learner motivation

. Lack of parental involvement

. No effective mechanism for TCPD

9. Parental poverty and pupils' barrier

Figure-5. Summary of the Findings.

\subsection{Deprivation and Disadvantage of the $Y L s$}

The only positive data that were gathered from the survey was the teachers' academic potential and length of teaching experience; however, they had also been the victims of circumstances created by lack of effective provisions of improving their English language skills, lack of appropriate CLT training, and unproductive supervision. Marxist theorist Pierre Bourdieu developed the theory of cultural capital which was applied to educational development. He hypothesized the concept as 'the habitus' and argues that middle class culture helps learners from the middle class use their cultural set of 'norms and values' to get themselves ahead of the working-class learners. Hence, the working class learners of CLT, particularly, from the rural regions, with poor socio-economic backgrounds are sure to lag behind in their educational achievement, let alone their 'flourishing' in learning English following CLT approach in Bangladesh (Bourdieu, 1977; Bourdieu \& Passeron, 1990; Huang, 2019). All kinds of inequality crop up in such an 'unhealthy and unkind' academic environment resulting in educational deprivation and inequality Bernstein (1973) and Bernstein (1977). These rural Bangladeshi learners of English are not only disadvantaged by the mismatch between policy and practice of CLT in the country since the 1990s but also lack of parental involvement with the process of learning English they must put up with is one of the reasons of their low motivation resulting low achievement in learning English. Love (2008) considers this lack of parental involvement as a 'unique stressor' causing psychological distress leading to low achievement of the African American college 
students learning English. Another case study by Rahming (2019) investigates 'social support and stress-related acculturative experience' of an English-speaking Afro-Caribbean female student and posits the unfriendly social environment for a foreign/second language learner can cause psychological distress. The English learners at the rural primary schools of Bangladesh are somehow the victims of such lack of 'social support' and parental involvement and an absence of English environment in the school, home, and social setting they live in and learn English are some of the crucial reasons for their academic and psychological distress. Ahmad, Hossain, and Bose (2004) claims in their study on the relationship between poverty, lack of parental involvement, low confidence, and low motivation, resulting in underachievement among the learners of English at secondary schools of rural Bangladesh.

Israel and Zuvalinyenga (2013) mentioned the theory of deprivation and talked of 'Deficit Hypothesis' in a Zimbabwean situation similar to that of rural Bangladesh, and recommended 'total overhaul of the whole system' through 'cooperative, and/or communicative' strategies of teaching-learning. Their study confirmed that a 'commandist' set of language teaching instruction would surely result in 'half-baked mimetic language graduates' (p.83). They argued that 'Deficit Hypothesis' acceptably ascertained language learning and literacy difficulties among working class YLs of English. This phenomenon is true of the Bangladesh CLT situation at primary schools of the hard-to-reach river-eroded rural regions of Bangladesh.

The data from the survey, the FGD and the interviews, directly or indirectly also reflect the views advocated by Bernstein's theory of Deficit Hypothesis and Bourdieu’s theory of cultural capital called the Habitus.

In order to share with the readers the first-hand knowledge of deprivation in rural primary schools of rivereroded dilapidated and ramshackle schools and the impoverished children who are sent to those extremely poor educational setting, the following two images are added to this study. These images refer to those schools where primary children in three different settings are allegedly supposed to create an 'English environment' for implementation of English curriculum designed as per CLT prescriptions.

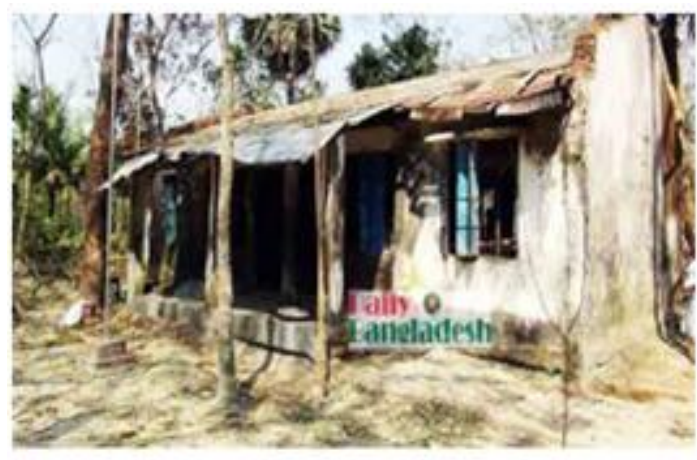

A rural school in a dilapidated condition

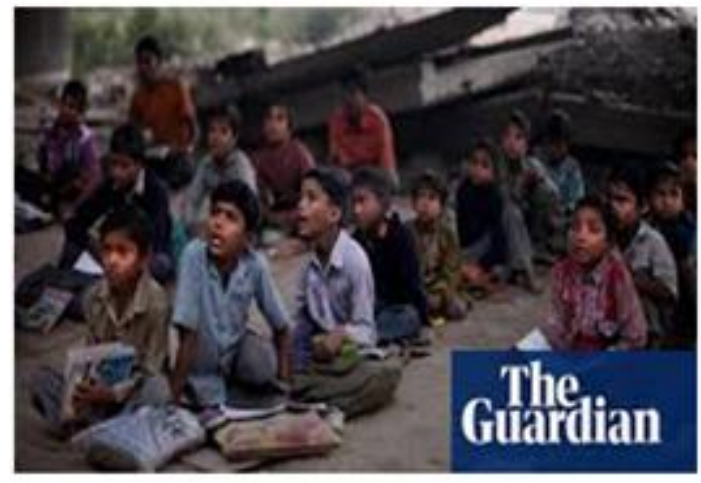

When the school roof touches the floor

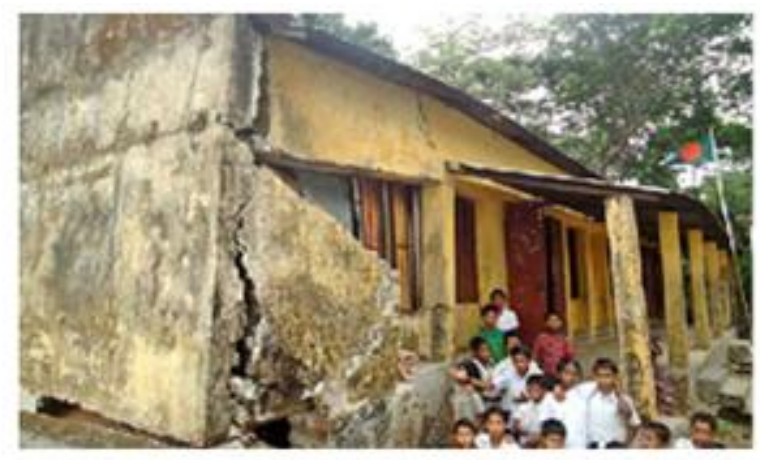

A ramshackle school with all risks

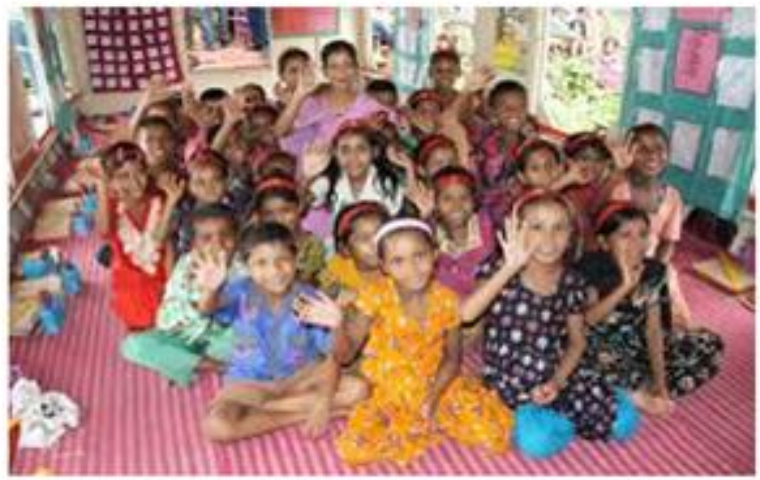

Boat school asked to provide 'English environment

Figure-6. A Display of Deprivation, Dilapidation, and disadvantage of the Rural Primary School Children in Bangladesh. 
Figure 6 with four photographs of rural primary schools of Bangladesh displays an overview of sufferings of the primary school learners of English in the rural regions of Bangladesh. It is a scenario of an utter lack of physical facilities where CLT prescribed 'English Environment' in dilapidated, tumbled-down and roofless schools. The children have no furniture to sit, no roof to take shelter during rainy and hot sunny days, let alone provisions for minimum health and sanitation.

\section{CONCLUSION}

The triangulation of the data in this research reflects light on the findings of the three previous studies on three separate areas of ELT conducted in the same location namely (Hamid, 2009) (Islam, 2019) and Hoque (2020). All three studies reveal the aspects of disadvantage, inequality, and deprivation of the rural learners of English. The first study Hamid (2009) uncovered the real 'social biography' of the English learners in the impoverished districts of Kurigram and Rangpur. It revealed their experience in poverty and getting a 'raw deal' from the delivery of English curricula. The second study Islam (2019) pinpointed the experience of learners with private tutoring in English and getting let down in accepting the discrepancy between the students coming from the well-to-do families and those coming from poor socio-economic backgrounds. The third study delved into the problems and predicaments of the teachers and learners in implementing the current English curricu Hoque (2020) following CLT approach in the primary schools of Rangpur and Kurigram districts. The findings of the three studies brought the message home together that the rural learners of English have been getting disservice and inequity, with very low/no achievement so far in comparison with their urban and well-to-do peers. This is a genuine case of deprivation, disadvantage, inequality, and un/under-achievement in education and in life.

The current study reflected the sum-total of these three studies and focuses more on the perils and problems that the pupils of the rural primary school must put up with. Added to the above observations from the three research reports, the findings on the current CLT scenario of primary schools in rural Bangladesh also focused on pupil aspects of academic trauma and suffering from CLT curriculum in terms of emotional and academic onslaught during the implementation of the CLT programmes at schools. It is recommended that teachers and academic administration should rethink, review and revamp the whole CLT approach, which has been implemented unsuccessfully in Bangladesh for the last two decades. IT is also recommended to include provisions of improving teachers' English language skills, pedagogic training in CLT, productive TCPD, user-friendly textbooks with culture sensitive contents and artefacts, permission for using mother tongue Bangla in teaching-learning English. Other suggestions include a good supply of educational technology equipment and electricity, home-school partnership, equal opportunities policy for all schools, a policy of health and safety for the YLs, and SEN (Special Educational Needs) service system for those with learning difficulties.

Funding: This study received no specific financial support.

Competing Interests: The authors declare that they have no competing interests.

Acknowledgement: All authors contributed equally to the conception and design of the study.

\section{REFERENCES}

Ahmad, A., Hossain, M., \& Bose, M. K. (2004). Inequality in the access to secondary education and rural poverty in Bangladesh: An analysis of household and school level data. Paper presented at the Workshop on Development in South Asia (World Bank, New Delhi, India, December 7-8).

Ansarey, D. (2012). Communicative language teaching in EFL contexts: Teachers' attitude and perception in Bangladesh. $A S A$ University Revierw, 6(1), 61-79.

Bashir, M., Afzal, M. T., \& Azeem, M. (2008). Reliability and validity of qualitative and operational research paradigm. Pakistan Journal of Statistics and Operation Research, 4(1), 35-45. Available at: https://doi.org/10.18187/pjsor.v4i1.59.

Bazeley, P. (2013). Qualitative data analysis: Practical strategies. London, England: Sage. 
Bernstein, B. (1973). Class, codes and control: Applied studies towards a sociology of language (Vol. 2). London: Routledge and Kegan Paul.

Bernstein, B. (1977). Primary socialisation, language and education: Class codes and control, towards a theory of educational transmissions (2nd ed. Vol. 3). London: Routledge and Kegan Paul.

Bourdieu, P. (1977). Cultural reproduction and social reproduction. In J. Karabel \& A. H. Halsey (Eds.), Power and ideology in education (pp. 487-511). New York: Oxford University Press.

Bourdieu, P. (1997). The forms of capital. In: Halsey AH, Lauder H, Brown P, et al. (eds) Education: Culture, Economy, Society (pp. 46-58). Oxford: Oxford University Press.

Bourdieu, P., \& Passeron, J.-C. (1990). Reproduction in education, society and culture (R. Nice, Trans.). London; Newbury Park; New Delhi: Sage.

Breen, R. L. (2006). A practical guide to focus-group research. Journal of Geography in Higher Education, 30(3), 463-475.

Bryman, A. (2004). Social research methods (2nd ed.). Oxford, England: Oxford University Press.

Burton, S., Eyres, I., \& McCormick, R. (2019). In "Sustainable english language teacher development at scale: Lesson from Bangladesh", edited by Eyres, I., McCormick ङ power, T. (2019) London: Bloomsbury Academic.

Canale, M., \& Swain, M. (1980). Theoretical bases of communicative approaches to second language teaching and testing. Applied Linguistics, 1 (1980) (pp. 1). UK: Oxford University Press, .

Carless, D. R. (2004). A contextualised examination of target language use in the primary school foreign language classroom. Australian Review of Applied Linguistics, 27(1), 104-1 19. Available at: https://doi.org/10.1075/aral.27.1.08car.

Chang, M. (2010). Factors affecting the implementation of communicative language teaching in Taiwanese college English classes. Taiwan: Minghsin University of Science and Technology.

Cohen, L., Manion, L., \& Morrison, K. (2000). Research methods in education. British Journal of Educational Studies, 55(4), 40-45.

Creswell, J. W. (2014). Research design: Qualitative, quantitative, and mixed methods approaches (4th ed.). United States of America: SAGE Publications, Inc.

Creswell, J. W., \& Plano, C. V. L. (2007). Designing and conducting mixed methods research. Thousand Oaks; London; New Delhi: Sage.

Directorate of Primary Education. (2019). Annual primary school census (pp. 01-129). Dhaka, Bangladesh: Ministry of Primary and Mass Education.

Dixon-Woods, M., Agarwal, S., Jones, D., Young, B., \& Sutton, A. (2005). Synthesising qualitative and quantitative evidence: A review of possible methods. Journal of Health Services Research \& Policy, 10(1), 45-53. Available at: https://doi.org/10.1258/1355819052801804.

EIA- English in Action. (2009). Baseline study 3: An observation study of the English lessons in primary and secondary schools in Bangladesh. Dhaka: Bangladesh EIA.

EIA-English in Action. (2009). An audit of current materials for teaching English in Bangladesh. Baseline Study, 4(62), 13-28.

Ellis, G. (1996). How culturally appropriate is the communicative approach? ELT Journal, 50(3), 213-218. Available at: https://doi.org/10.1093/elt/50.3.213.

English in Action. (2009). An assessment of spoken Eglish competence among school students, Teachers and Adults in Bangladesh. Baseline Study, 23(4), 1-46.

Erling, J., \& Hamid, O. (2016). English-in-education policy and planning in Bangladesh: A critical examination in Kirkpatrik, R. (ed.) English Education Policy in Asia and the Middle East (pp. 25-48). Dordrecht: Springer.

Erling., E. J., \& Hamid, M. O. (2016). English-in-education policy and planning in Bangladesh: A critical examination. In English language education policy in Asia (pp. 25-48). Cham: Springer.

Exley, B. (2004). Indonesian EFL Curricula: What content knowledge demands do they make of Australian teachers? Performing Educational Research: Theories, Methods and Practices, 32(3), 363-373.

Farooqui, S. (2014). The struggle to teach in English: A case study in Bangladesh. Journal of Education and Human Development, 3(2), 441-457. 
Greene, J. C., Caracelli, V. J., \& Graham, W. F. (1989). Toward a conceptual framework for mixed-method evaluation designs. Educational Evaluation and Policy Analysis, 11(3), 255-274. Available at: https://doi.org/10.3 102/0162373701 1003255.

Hamid, O. (2009). Sociology of language learning: Social biographies and school English achievement in rural Bangladesh. A Thesis Submitted for the Degree of Doctor of Philosophy at the University of Queensland in February 2009.

Hasan, K. (2004). A linguistic study of English language curriculum at the secondary level in Bangladesh -a communicative approach to curriculum development. Language in India: Strength for Today and Bright Hope for Tomorrow, 4(8), 3-30.

Hassan., M. K. (2013). Teachers' and students' percieved difficulties in implementing communicative language teaching in Bangladesh: A critical study. Unpublished Ph.D. Dissertation. The Open University, UK, Milton Keynes.

Hoque, M. S. (2020). Communicative language teaching (CLT) approach: Its predicaments and prospects in the primary schools of rural Bangladesh. A Thesis Submitted for the Degree of Doctor of Philosophy at The University Sains Islam Malaysia, Nilai. Malaysia.

Hossain, M. K. (2012). Kurigram district. In Sirajul Islam and Ahmed A. Jamal (ed.) (2nd ed.). Banglapedia: National Encyclopedia of Bangladesh. Asiatic Society of Bangladesh.

Hossain, M. A., Nessa, M., \& Kafi, M. A. (2015). Challenges of teaching English language at the primary level schools in Bangladesh. Banglavision Research Journal, 15(1), 07-18.

Huang, X. (2019). Understanding Bourdieu-cultural capital and habitus. European Review Studies 11(3), 45. Available at: https://doi.org/10.5539/res.v11n3p45.

Hussain, G. (2017). An evaluation of ELT situation in higher education institutions in Punjab, Pakistan. European Journal of English Language Teaching, 2(3), 1-25.

Islam, M. M. (2019). Private tutoring of english language: Motivational and societal factors in the lived experiences Bangladeshi higher secondary students. Ph,D. Thesis Submitted at the University Malay (UM), Malaysia.

Israel, M., \& Zuvalinyenga, D. Z. (2013). Educational implications of the deficit/deprivation hypothesis in L2 situations: A case of Zimbabwe Muvindi Israel and Zuvalinyenga Dorcas Bindura University of Science Education. International Journal of English and Literature, 4(6), 283-287.

Jahbel, K. S. (2017). Communicative language teaching'and its relevance to the Libyan English language teaching context. Premise: Journal of English Education and Applied Linguistics, 6(1), 1-7. Available at: https://doi.org/10.24127/pj.v6i1.762.

Jick, T. D. (1979). Mixing qualitative and quantitative methods: Triangulation in action. Administrative Science Quarterly, 24(4), 602-611. Available at: https://doi.org/10.2307/2392366.

Johnson, R., \& Onwuegbuzie, A. (2004). Mixed methods research: A research paradigm whose time has come. Eductational Researcher, 33(7), 14-26. Available at: https://doi.org/10.3102/0013189x033007014.

Julie, Y. F. (2013). The pedagogical maze: Retrospection on CLTHong Kong Dan Lu1, Language Center. Hong Kong, China: Hong Kong Baptist University.

Karim, K. M. R. (2004). Teachers' perceptions, attitudes, and expectations about communicative language teaching (CLT) in post-secondary education in Bangladesh. Masters Dissertation: University of Victoria, Newzealand.

Karim, A., Mohamed, A. R., \& Rahman, M. M. (2017). EIA- a teacher education project in Bangladesh: An analysis from diversified perspective. International Journal of Instruction, 10(4), 51-66. Available at: https://doi.org/10.12973/iji.2017.1044a.

Kirkwood, A. (2013). English for communication in Bangladesh: Baseline research to establish the pre-existing environment for the 'English in Action'project. System, 41(3), 866-879. Available at: https://doi.org/10.1016/j.system.2013.09.002.

Li, D. (1998). "It's always more difficult than you plan and imagine": Teachers' perceived difficulties in introducing the communicative approach in South Korea. TESOL Quarterly, 32(4), 677-703. Available at: https://doi.org/10.2307/3588000.

Liao, X. (2000). Communicative language teaching innovation in China: Difficulties and solutions. ERIC Database, (ED443294). Retrieved form: http://www.eric.ed.gov/PDFS/ED443294.pdf-703.on. 
Love, K. M. (2008). Parental attachments and psychological distress among African American college students. Journal of College Student Development, 49(1), 31-40. Available at: https://doi.org/10.1353/csd.2008.0000.

Luke, M. M., \& Goodrich, K. M. (2019). Focus group research: An intentional strategy for applied group research? Journal for Specialists in Group Work, 44(2), 77-81. Available at: https://doi.org/10.1080/01933922.2019.1603741.

Rahman, K. A., \& Rahman, M. F. (2012). Change initiatives in English in action intervened primary schools in Bangladesh. Mevlana International Journal of Education, 2(1), 15-24.

Rahming, S. (2019). Social support and stress-related acculturative experiences of an English-speaking Afro-Caribbean female student in U.S. higher education. Journal of International Students, 9(4), 1055-1073. Available at: https://doi.org/10.32674/jis.v9i4.343.

Raihan, M. A., \& Han, S. L. (2013). Integrating web-based e-learning in TVET to enhance the literacy and socio-economic condition for sustainable development of Bangladesh. Journal of Education and Practice, 4(1), 1-12.

Rao, Z. (2002). Chinese students' perceptions of communication and non-.communicative activities in EFL classroom. ELT Journal, 30(2), 85-105.

Richards, J. C., \& Rodgers, T. S. (2001). Approaches and methods in language teaching (2nd ed.). New York: Cambridge University Press.

Richards, J. C. (2006). Communicative language teaching today (pp. 10013-12473). New York, USA: Cambridge University Press 32 Avenue of the Americas.

Savignon, S. J. (2002). Communicative languageteaching: Linguistictheory and classroompractice. London: Yale University Press.

Shrestha, P. N. (2013). English language classroom practices: Bangladeshi primary school children's perceptions. RELC Journal, 44(2), 147-162. Available at: https://doi.org/10.1177/0033688213488466.

Stirling, D. (2014). Motivation in education. Aichi Universities English Education Research Journal, 29(2013), 51-72.

Sultana, S. (2018). English language in Bangladesh: Challenges and prospects. Language in India, 18(3), 1-11.

Tashakkori, A., \& Teddlie, C. (2010). SAGE handbook of mixed methods in social and behavioral research (2nd ed.). Thousand Oaks, CA: Sage.

World Bank. (2021). World Bank Bangladesh country overview. Retrieved from https://www.worldbank.org/en/country/bangladesh/overview\#: :text=Bangladesh\%20has\%20an\%20impressive\%2 otrack,than\%20\%2430\%20billion\%20in\%20support.

Yin, R. K. (2006). Mixed methods research: Are the methods genuinely integrated or merely parallel. Research in the Schools, $13(1), 41-47$.

Yu, L. (2001). Communicative language teaching in China: Progress and resistance. TESOL Quarterly, 35(1), 194-198. Available at: https://doi.org/10.2307/3587868. 